\title{
Assessment of Outcome of Hepatic Resection for Extremely Elderly Patients With a Hepatic Malignancy
}

\author{
TAKASHI HORIUCHI, KOICHIRO HARUKI, HIROAKI SHIBA, TARO SAKAMOTO, NOBUHIRO SAITO, \\ YOSHIHIRO SHIRAI, RYOTA IWASE, YUKI FUJIWARA and KATSUHIKO YANAGA \\ Department of Surgery, The Jikei University School of Medicine, Tokyo, Japan
}

\begin{abstract}
Background/Aim: We aimed to assess surgical outcome and long-term survival after elective hepatic resection for hepatocellular carcinoma (HCC) and colorectal liver metastasis (CRLM) in patients aged 80 years or older. Patients and Methods: This study included 100 patients aged 70 years or older, who underwent hepatic resection for HCC or CRLM between January 2000 and December 2012. Outcomes and clinicopathological data were compared between the elderly (aged 70-79 years; $n=84$ ) and extremely elderly groups (aged 80 years or older; $n=16)$. Results: Incidence of postoperative complications, in-hospital mortality, and postoperative OS in the extremely elderly group were comparable with those of the elderly group. In patients with $\mathrm{HCC}$, the extremely elderly group was associated with shorter DFS $(p=0.030)$ in univariate analysis, while multivariate analysis showed significant and independent factors of cancer recurrence. Conclusion: Hepatic resection for HCC and CRLM in patients aged 80 years and older may be safe and acceptable with appropriate selection. For HCC in patients aged 80 years and older, hepatic resection may be effective when negative surgical margins can be achieved.
\end{abstract}

The number and proportion of the elderly population have increased progressively as a result of advances in medicine. Current population dynamics show that $20 \%$ of the population in developed countries is expected to be over 65 years by 2025 (1). In Japan, the average life expectancy was 79.59 years in males and 86.44 years in females in 2009 . More than $50 \%$ of primary and metastatic liver cancers occur in patients aged $>65$ years (2). Under such conditions, the assessment of safety and outcome after hepatic resection for extremely elderly patients is important.

Correspondence to: Takashi Horiuchi, The Jikei University School of Medicine, 3-25-8, Nishi-Shinbashi, Minato-ku, Tokyo 105-8461, Japan. Tel: +81 334331111 ext. 3401, Fax: +81 334331230, e-mail: horiuchi@jikei.ac.jp

Key Words: Hepatic resection, extremely elderly patient, hepatocellular carcinoma, colorectal liver metastasis.
Hepatic resection is the only possible treatment to potentially cure the patients with hepatocellular carcinoma (HCC) or colorectal liver metastasis (CRLM), and the safety of hepatic resection in elderly patients (70 years and older) has been reported by several centers $(3,4)$. However, there were only few reports of hepatic resection for patients aged 80 and older with hepatobiliary malignancies. The aim of this study was the assessment of surgical outcome and longterm survival after elective hepatic resection for HCC and CRLM in patients aged 80 years and older.

\section{Patients and Methods}

This study included 100 patients aged 70 years or older, who underwent hepatic resection for HCC or CRLM between January 2000 and December 2012 at the Department of Surgery, Jikei University Hospital, Tokyo, Japan. The patients were classified into two groups: elderly group (aged 70 to 79 years; $n=84$ ) and extremely elderly group (aged 80 years or older; $n=16$ ). We retrospectively assessed clinicopathological variables, and disease-free as well as overall survival between elderly group and extremely elderly group by univariate analysis. The factors consisted of the following 24 factors: age, gender, coexistence diseases, pathological diagnosis, type of hepatic resection, duration of operation, intraoperative blood loss, intraoperative blood transfusion, in-hospital mortality, postoperative hospital stay, incidence of postoperative complications, tumor factor based on tumor pathology in HCC (American Joint Committee on Cancer/ International Union Against Cancer), liver metastasis grade in CRLM (Japanese classification of colorectal carcinoma), microscopic curability, hepatitis virus status, Child-Pugh classification, retention rate of indocyanine green at $15 \mathrm{~min}$ $\left(\mathrm{ICG}_{\mathrm{R} 15}\right.$ ), tumor differentiation, serum alpha-fetoprotein (AFP), serum carcinoembryonic antigen (CEA), preoperative transcatheter arterial embolization (TAE) and disease-free as well as overall survival. The association of clinicopathologic variables with diseasefree survival after hepatic resection for HCC was assessed by univariate and multivariate analysis.

Generally, the extent of hepatic resection was decided based on $I_{C G_{15}}$ before surgery and in reference to the hepatic reserve as described by Miyagawa et al. (5). The type of resection was classified as anatomical resection (extended lobectomy, lobectomy, segmentectomy or subsegmentectomy) and non-anatomical limited partial resection. 
Table I. Assessment of clinicopathological variables and outcome after hepatic resection between elderly and extremely elderly patients by univariate analysis.

\begin{tabular}{|c|c|c|c|}
\hline Factor & Elderly group $(\mathrm{n}=84)$ & Extremely elderly group $(n=16)$ & $p$-Value \\
\hline Age (years) & $73.5 \pm 2.5^{*}$ & $83.0 \pm 3.2$ & \\
\hline Gender (male:female) & $61: 23$ & $10: 6$ & 0.296 \\
\hline \multicolumn{4}{|l|}{ Concomitant disease } \\
\hline Hypertension, n (\%) & $51(61)$ & $10(63)$ & 0.964 \\
\hline Diabetes mellitus, n (\%) & $19(23)$ & $6(38)$ & 0.171 \\
\hline Hyperlipidemia, n (\%) & $6(7)$ & $4(25)$ & 0.051 \\
\hline Cardiac disease, $\mathrm{n}(\%)$ & $6(7)$ & $1(6)$ & 0.689 \\
\hline Pathological diagnosis & & & 0.176 \\
\hline Hepatocellular carcinoma, n (\%) & $52(62)$ & $7(44)$ & \\
\hline Colorectal liver metastasis, n (\%) & $32(38)$ & $9(56)$ & \\
\hline Type of hepatic resection & & & 0.228 \\
\hline Partial liver resection, $\mathrm{n}(\%)$ & $40(48)$ & $5(31)$ & \\
\hline Anatomical liver resection, $\mathrm{n}(\%)$ & $44(52)$ & $11(69)$ & \\
\hline Duration of operation (min) & $366.9 \pm 148.4$ & $367.3 \pm 166.0$ & 0.993 \\
\hline Intraoperative blood loss (ml) & $1,115.1 \pm 1,218.6$ & $852.2 \pm 1,152.0$ & 0.427 \\
\hline Intraoperative blood transfusion, $\mathrm{n}(\%)$ & $38(45)$ & $10(63)$ & 0.205 \\
\hline In-hospital mortality, n (\%) & $1(1)$ & 0 & 0.840 \\
\hline Postoperative hospital stay (days) & $16.4 \pm 9.7 *$ & $17.8 \pm 12.4^{*}$ & 0.602 \\
\hline \multicolumn{4}{|l|}{ Postoperative complication } \\
\hline Hepatic failure, n $(\%)$ & $1(1)$ & 0 & 0.840 \\
\hline Surgical site infection, $\mathrm{n}(\%)$ & $12(14)$ & 0 & 0.108 \\
\hline Pulmonary complication, $\mathrm{n}(\%)$ & $12(14)$ & $1(6)$ & 0.687 \\
\hline Bile leakage, $\mathrm{n}(\%)$ & $8(10)$ & $1(6)$ & 0.560 \\
\hline Delirium, $\mathrm{n}(\%)$ & $1(1)$ & 0 & 0.840 \\
\hline
\end{tabular}

$\mathrm{n}$ : Number of patients; $*$ mean $\pm \mathrm{SD}$.

Hepatic failure was defined as an increased international normalized ratio (INR) and concomitant hyperbilirubinemia on or after postoperative day (POD) 5 and other obvious causes for the observed biochemical and clinical alterations, such as biliary obstruction were excluded. Furthermore, the need for clotting factors such as fresh frozen plasma (FFP) to maintain normal INR on or after POD 5 in combination with hyperbilirubinemia was considered hepatic failure (6). Bile leakage was defined as discharge of fluid with an increased bilirubin concentration via the intra-abdominal drains on or after POD 3 or defined as the need for radiologic intervention (i.e., interventional drainage) or relaparotomy for biliary collections or bile peritonitis, respectively (7). Surgical site infection was defined as surgical wound infection that affected superficial tissues (skin and subcutaneous layer) or the deeper tissues (deep incisional or organ-space) of the incision according to the definition of the Centers for Disease Control and Prevention (CDC) (8). Pulmonary complications were defined as postoperative pneumonia; pleural effusion that required thoracentesis; or postoperative respiratory failure with pyrexia, dyspnea, and a pulmonary infiltrate on chest X-ray. Delirium was defined as an acute decline in cognitive function and attention (9).

Recurrences of HCC and CRLM were defined as newly detected hepatic or extrahepatic tumors as shown by ultrasonography, computed tomography, magnetic resonance image or angiography, with or without an increase in serum AFP, or protein induced by vitamin $\mathrm{K}$ absence or antagonist-II (PIVKA-II) in HCC, and CEA or carbohydrate antigen 19-9 (CA19-9) in CRLM. This retrospective study was approved by the Ethics Committee of The Jikei University School of Medicine [No: 27-177(8062)].

Statistical analysis. The categorical variables were expressed as numbers and percentages (\%), and continuous variables as mean \pm standard deviation (SD). Univariate analysis was performed using the non-paired Student's test, Chi-square test or Fisher's exact test, as appropriate. Univariate analysis of disease-free and overall survival was performed using the Log-rank test. The Cox proportional regression model with backward elimination approach was used for multivariate analysis to assess predictors of disease-free survival in HCC patients. All $p$-values were considered statistically significant when the associated probability was less than 0.05 .

\section{Results}

Annual changes in the number of hepatic resections for patients with $70 \leq$ years $<80$, and $\geq 80$ years. During this study period, 16 of 100 patients aged 70 or over who underwent hepatic resection for HCC or CRLM were aged 80 or over. Annual changes in the number of hepatic resections for patients with $70 \leq$ years $<80$ and $\geq 80$ years are shown in Figure 1. The number of patients aged 70 years or over gradually increased during the study period. 


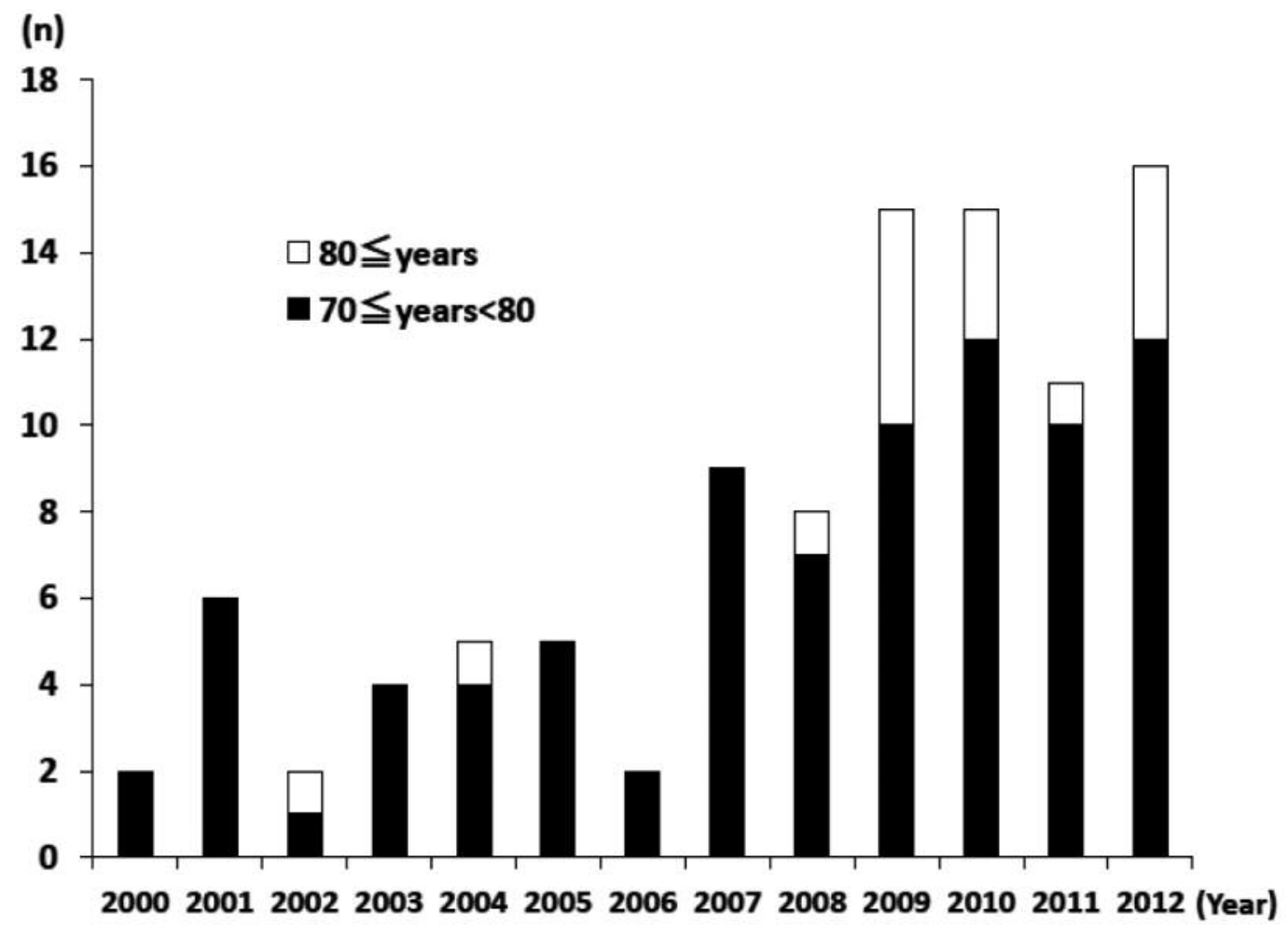

Figure 1. Annual changes in the number of hepatic resections for patients aged $70 \leq y e a r s<80$ and $\geq 80$ years at our institution during the period between 2000 and 2012. The number of patients aged 70 years or older gradually increased during the study period.

Clinicopathological variables and outcome after hepatic resection between elderly and extremely elderly patients. Table I lists the comparison of patient's clinicopathological variables and outcome after hepatic resection between elderly and extremely elderly groups. Co-morbidity including hypertension, diabetes mellitus, hyperlipidemia, and cardiac disease were comparable between the two groups. As per the surgical outcome, there was one (1.1\%) in-hospital mortality in the elderly group, and none in the extremely elderly group. Incidences of postoperative complications including hepatic failure, surgical site infection, pulmonary complications, bile leakage, and delirium in both groups were comparable.

Pathological findings and microscopic curability. Table II lists the comparison of pathological findings and clinical variables in HCC and CRLM between the two groups. HCC stage and CRLM grade were comparable between the two groups. Achievement of microscopically curative resection for HCC and CRLM in the elderly group was $56 \%$ and $81 \%$, respectively, and that in the extremely elderly group was $57 \%$ and $100 \%$, respectively $(p=0.098$ and 0.202 , respectively). Preoperative TAE for HCC was significantly more frequent in extremely elderly patients than that in elderly patients $(p=0.026)$. Other variables in HCC and CRLM were comparable between the two groups.

Disease-free and overall survival in both HCC and CRLM patients. Figure 2 indicates the Kaplan-Meier curves of disease-free (Figure 2A) and overall survival (Figure 2B) after hepatic resection for HCC. The disease-free 1- and 3year survival rates after hepatic resection were $75 \%$ and $33 \%$ in the elderly group, and $50 \%$ and $0 \%$ in the extremely elderly group, respectively $(p=0.030)$. The overall 1- and 3- year survival rates were $92 \%$ and $81 \%$ in the elderly group, and $100 \%$ and $38 \%$ in the extremely elderly group, respectively $(p=0.370)$. Figure 3 indicates the Kaplan-Meier curves of disease-free (Figure 3A) and overall survival (Figure 3B) after hepatic resection for patients with CRLM. The disease-free 1- and 3- year survival rates after hepatic resection were $55 \%$ and $23 \%$ in the elderly group, and $33 \%$ and $33 \%$ in the extremely elderly group, respectively $(p=0.565)$. The overall 1 - and 3 -year survival rates were $93 \%$ and $55 \%$ in the elderly group, and $78 \%$ and $52 \%$ in the extremely elderly group, respectively $(p=0.486)$. 
A

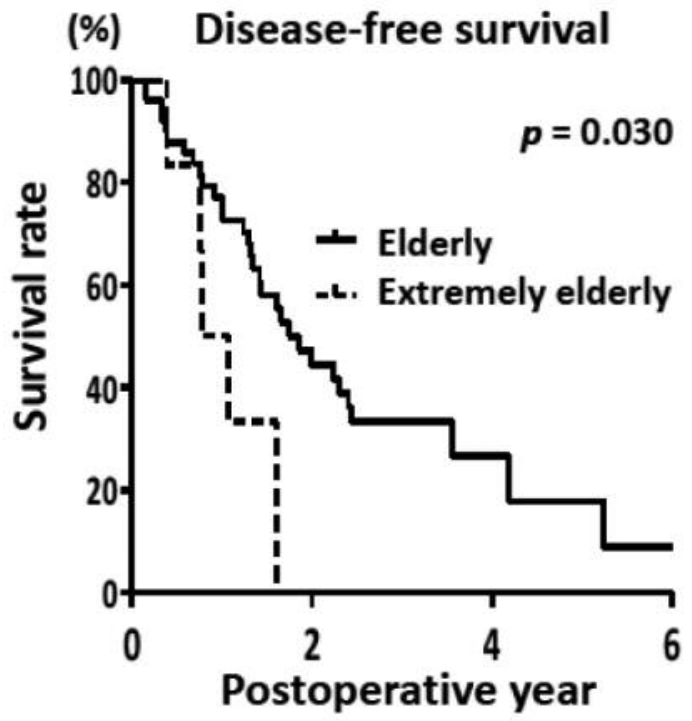

B

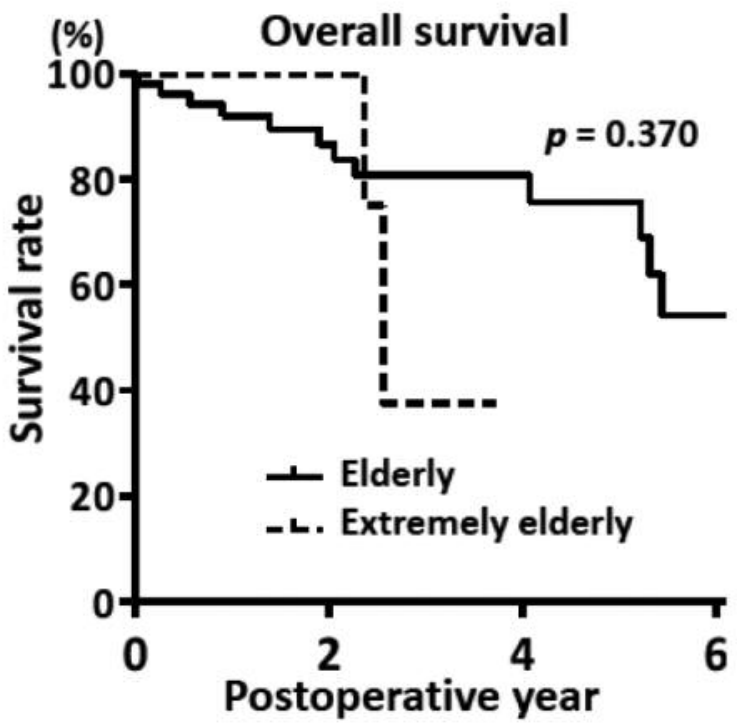

Figure 2. Cumulative disease-free survival (A) and overall survival (B) for extremely elderly and elderly groups of patients with hepatocellular carcinoma after hepatic resection.
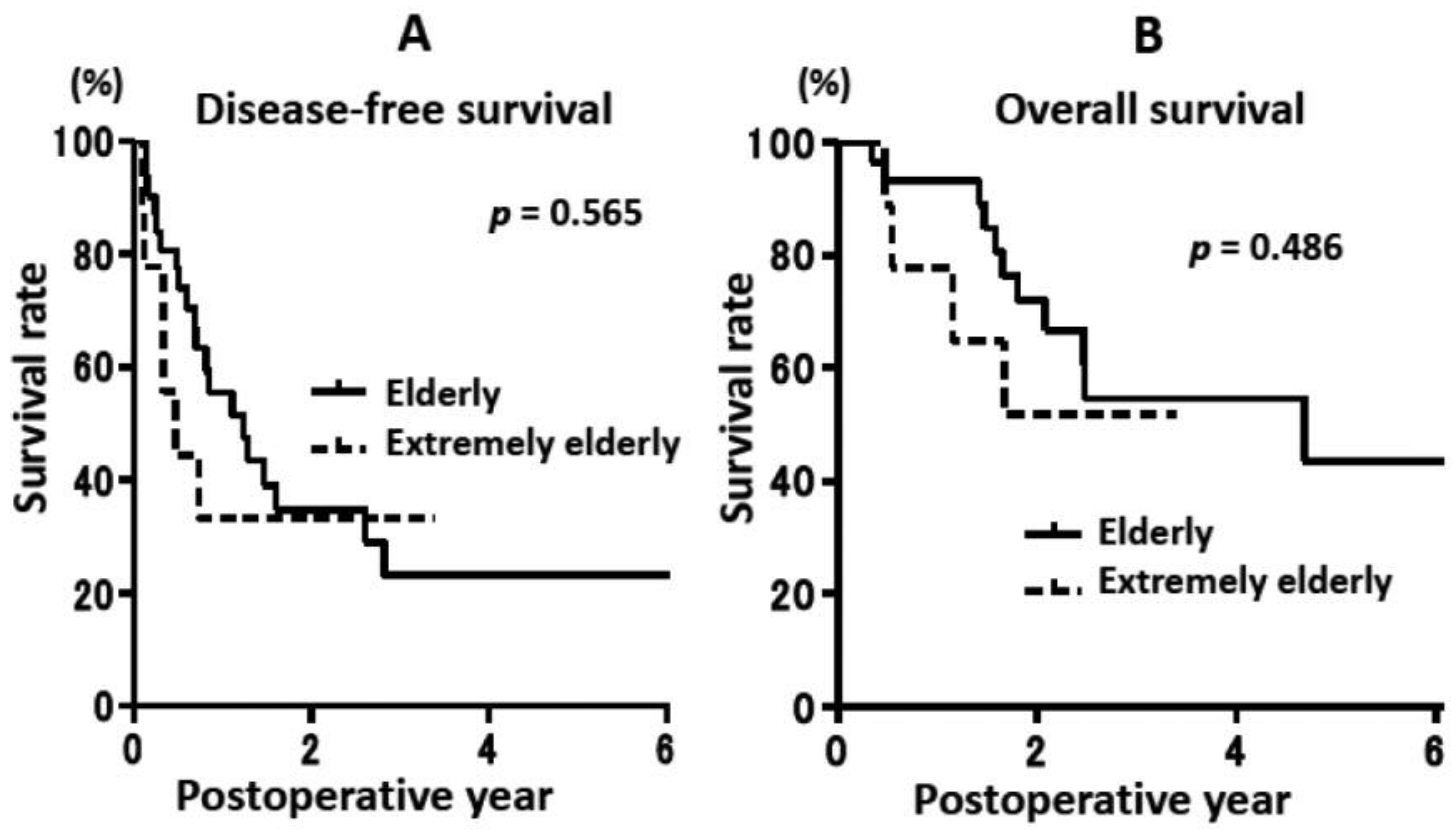

Figure 3. Cumulative disease-free survival (A) and overall survival (B) for extremely elderly and elderly groups of patients with colorectal liver metastasis after hepatic resection.

Univariate and multivariate analyses of clinicopathological variables in relation to disease-free survival after hepatic resection for HCC. Table III lists the relationship between the clinicopathological variables and disease-free survival after hepatic resection for HCC. In the univariate analysis, disease-free survival was significantly worse in extremely elderly patients $(p=0.030)$, male $(p=0.002), \mathrm{T} 3$ or T4 $(p=0.021)$, serum AFP $\geq 10 \mathrm{ng} / \mathrm{ml}(p=0.043)$, and presence of preoperative TAE $(p=0.022)$. In multivariate analysis, male $(p=0.002)$, positive surgical margin $(p=0.021)$, and serum $\mathrm{AFP} \geq 10 \mathrm{ng} / \mathrm{ml} \quad(p=0.035)$ were independent and significant predictors of disease-free survival. 
Table II. Pathological findings and clinical variables in hepatocellular carcinoma and colorectal cancer liver metastasis.

\begin{tabular}{|c|c|c|c|}
\hline Factor & Elderly group $(\mathrm{n}=84)$ & Extremely elderly group $(n=16)$ & $p$-Value \\
\hline \multicolumn{4}{|l|}{ Hepatocellular carcinoma $(n=59)$} \\
\hline Stage, n $(\%)$ & & & 0.337 \\
\hline I & $26(50)$ & $3(43)$ & \\
\hline II & $24(46)$ & $3(43)$ & \\
\hline III & $2(4)$ & $1(14)$ & \\
\hline Microscopic curability, n (\%) & & & 0.098 \\
\hline A & $29(56)$ & $4(57)$ & \\
\hline B & $20(38)$ & $1(14)$ & \\
\hline $\mathrm{C}$ & $3(6)$ & $2(29)$ & \\
\hline Hepatitis virus (HBV or HCV:no) & $33: 19$ & $2: 5$ & 0.089 \\
\hline Child-Pugh classification (A:B) & $47: 5$ & $7: 0$ & 0.519 \\
\hline $\mathrm{ICG}_{\mathrm{R} 15}(\%)$ & $17.7 \pm 9.8$ & $18.4 \pm 8.1$ & 0.416 \\
\hline Tumor differentiation, $\mathrm{n}(\%)$ & & & 0.064 \\
\hline Well or Moderately & $46(88)$ & $4(57)$ & \\
\hline Poorly & $6(12)$ & $3(43)$ & \\
\hline Serum AFP, n (\%) & & & 0.470 \\
\hline$\geq 10 \mathrm{ng} / \mathrm{ml}$ & $30(58)$ & $5(71)$ & \\
\hline$<10 \mathrm{ng} / \mathrm{ml}$ & $19(37)$ & $2(29)$ & \\
\hline Unknown & $3(5)$ & 0 & \\
\hline Preoperative TAE (yes:no) & $8: 44$ & $4: 3$ & 0.026 \\
\hline \multicolumn{4}{|l|}{ Colorectal liver metastasis $(n=41)$} \\
\hline Grade, $\mathrm{n}(\%)$ & & & 0.415 \\
\hline A & $15(47)$ & $6(67)$ & \\
\hline $\mathrm{B}$ & $11(34)$ & $1(11)$ & \\
\hline $\mathrm{C}$ & $4(13)$ & $2(22)$ & \\
\hline Unknown & $2(6)$ & 0 & \\
\hline Microscopic curability, n (\%) & & & 0.202 \\
\hline Curative & $26(81)$ & $9(100)$ & \\
\hline Non-curative & $6(19)$ & 0 & \\
\hline Serum CEA, n (\%) & & & 0.676 \\
\hline$\geq 5 \mathrm{ng} / \mathrm{ml}$ & $26(81)$ & $8(89)$ & \\
\hline$<5 \mathrm{ng} / \mathrm{ml}$ & $4(13)$ & $1(11)$ & \\
\hline Unknown & $2(6)$ & 0 & \\
\hline
\end{tabular}

$\mathrm{n}$ : Number of patients; AFP: alpha-fetoprotein; $\mathrm{ICG}_{\mathrm{R} 15}$ : retention rate of indocyanine green at $15 \mathrm{~min}$; TAE: transcatheter arterial embolization; CEA: carcinoembryonic antigen.

\section{Discussion}

Because of improvements in surgical techniques and perioperative supportive care, the mortality and morbidity rates of elective hepatic resection have decreased, the rate of hepatic resections for patients aged 70 years or older with a good general condition has increased, and the outcome is improving (10). In the 21th century, the average life expectancy at birth has lengthened to over 80 years in many countries (11), and therefore, assessment of therapeutic outcome after elective hepatic resection for extremely elderly patients with hepatobiliary malignancies such as HCC or CRLM is important. Several investigators indicated safety and validity of hepatic resection for patients aged 80 years and older in mortality, morbidity, and benefit for patient's survival (12). Melendez et al. reported that patient age did not contribute to in-hospital mortality upon extended hepatic resection (more than 4 sub-segments) (13). Huang et al. reported that extremely elderly patients were not at risk for a worse outcome such as duration of operation, blood loss, transfusion, postoperative complication, and postoperative hospital stay (3). Therefore, assessment of each risk factor for postoperative morbidity and mortality after hepatic resection for extremely elderly patients is important. In the present study, there were no significant differences in postoperative complications between the two groups. Extremely elderly HCC patients were associated with worse disease-free survival by univariate analysis, which, however, was not a significant poor prognostic factor by multivariate analysis. For disease-free survival, multivariate analysis showed tumor-related factors, such as serum AFP and surgical margin, to be associated with cancer recurrence. As for CRLM, extremely elderly patients showed comparable long- 
Table III. Univariate and multivariate analyses of clinicopathological variables in relation to disease-free survival after liver resection of hepatocellular carcinoma.

\begin{tabular}{|c|c|c|c|c|c|}
\hline \multirow[t]{2}{*}{ Factor } & \multirow[t]{2}{*}{$\mathrm{n}$} & \multicolumn{2}{|c|}{ Univariate analysis } & \multicolumn{2}{|c|}{ Multivariate analysis } \\
\hline & & Hazard ratio $(95 \% \mathrm{CI})$ & $p$-Value & Hazard ratio $(95 \% \mathrm{CI})$ & $p$-Value \\
\hline \multicolumn{6}{|l|}{ Age (years) } \\
\hline$\geq 80$ & 7 & 4.912 & 0.030 & & NS \\
\hline $70-79$ & 52 & $(1.164-20.73)$ & & & \\
\hline \multicolumn{6}{|l|}{ Gender } \\
\hline Male & 45 & 3.095 & 0.002 & 7.267 & 0.002 \\
\hline Female & 14 & $(1.523-6.289)$ & & $(2.082-25.370)$ & \\
\hline \multicolumn{6}{|l|}{ Hepatitis virus } \\
\hline $\mathrm{HBV}$ or $\mathrm{HCV}$ & 35 & 0.749 & 0.425 & & NS \\
\hline No & 24 & $(0.369-1.523)$ & & & \\
\hline \multicolumn{6}{|l|}{$\mathrm{T}$ factor } \\
\hline $\mathrm{T} 3$ or $\mathrm{T} 4$ & 28 & 2.308 & 0.021 & & NS \\
\hline $\mathrm{T} 1$ or $\mathrm{T} 2$ & 31 & $(1.138-4.684)$ & & & \\
\hline \multicolumn{6}{|l|}{ Type of resection } \\
\hline Anatomical & 33 & 1.080 & 0.824 & & NS \\
\hline Partial & 26 & $(0.549-2.124)$ & & & \\
\hline \multicolumn{6}{|l|}{ Coexistent diseases } \\
\hline HT or DM or HL or CD & 28 & 1.314 & 0.487 & & NS \\
\hline No & 31 & $(0.608-2.839)$ & & & \\
\hline \multicolumn{6}{|c|}{ Intraoperative blood transfusion } \\
\hline Yes & 18 & 1.568 & 0.247 & & NS \\
\hline No & 41 & $(0.732-3.360)$ & & & \\
\hline \multicolumn{6}{|l|}{ Child's classification } \\
\hline A & 54 & 1.297 & 0.632 & & NS \\
\hline $\mathrm{B}$ & 5 & $(0.448-3.761)$ & & & \\
\hline \multicolumn{6}{|l|}{$\mathrm{ICG}_{\mathrm{R} 15}(\%)$} \\
\hline$\geq 15$ & 37 & 1.081 & 0.820 & & NS \\
\hline$<15$ & 22 & $(0.552-2.115)$ & & & \\
\hline \multicolumn{6}{|l|}{ Tumor differentiation } \\
\hline Well or Moderately & 50 & 0.627 & 0.342 & & NS \\
\hline Poorly & 9 & $(0.239-1.642)$ & & & \\
\hline \multicolumn{6}{|l|}{ Surgical margin } \\
\hline Positive & 5 & 1.872 & 0.301 & 4.088 & 0.021 \\
\hline Negative & 54 & $(0.571-6.137)$ & & $(1.237-13.510)$ & \\
\hline \multicolumn{6}{|l|}{ Serum AFP } \\
\hline$\geq 10 \mathrm{ng} / \mathrm{ml}$ & 35 & 2.093 & 0.043 & 2.491 & 0.035 \\
\hline$<10 \mathrm{ng} / \mathrm{ml}$ & 21 & $(1.025-4.274)$ & & $(1.069-5.806)$ & \\
\hline \multicolumn{6}{|l|}{ Preoperative TAE } \\
\hline Yes & 12 & 2.988 & 0.022 & & NS \\
\hline No & 47 & $(1.168-7.644)$ & & & \\
\hline
\end{tabular}

HT: Hypertension; DM: diabetes mellitus; HL: hyperlipidemia; CD: cardiac disease; $\mathrm{ICG}_{\mathrm{R} 15}$ : retention rate of indocyanine green at 15 min; $\mathrm{AFP}$ : alpha-fetoprotein; TAE: transcatheter arterial embolization.

term outcomes. These results suggest that limited hepatic resection was preferred in extremely elderly patients with $\mathrm{HCC}$, because impaired hepatic functional reserve had to be considered. As a result, extremely elderly HCC patients had achieved less microscopically curative resection rate and more frequently received TAE before operation. Kaibori et al. demonstrated that hepatic resection decreases the risk of tumor recurrence and improves overall survival in patients aged $\geq 75$ years with primary HCC tumors of $\leq 3.0 \mathrm{~cm}$ in diameter (14).
Thus, hepatic resection may be effective for patients aged 80 years or older whose hepatic resection can be performed with negative surgical margin.

Potential limitations of the present study are its retrospective nature and being a single-institutional study. Also, small number of patients is associated with selection bias including the liver functional reserve and the concomitant disease. Therefore, a large-scale study is needed to verify the results. 
Enhanced recovery after surgery (ERAS) protocols have been developed to attenuate the surgical stress response, improve recovery, and decrease postoperative complications and length of hospital stay (15). Perioperative care among centers that perform liver resections varies substantially and elements of ERAS programs have already been implemented as part of daily surgical practice (16). In liver surgery, a systematic review of ERAS demonstrated that length of hospital stay was reduced and functional recovery was accelerated without compromising morbidity or mortality rates, and readmission rates were not significantly increased (17). In colorectal surgery for elderly patients, Bagnall et al. demonstrated that enhanced recovery after colorectal surgery seems to be safe in the elderly (18) and Pawa et al. found that patients aged over 80 years were able to achieve early mobilization, statistically similar to patients under 80 years (19).

Hepatic resection has a relatively high incidence of postoperative complications, but adequate treatments for postoperative complications after hepatic resection including liver failure, bile leakage, and pulmonary complication reduce mortality rates (20). The choice of appropriate therapeutic methods, as well as immediate management of complications after hepatic resection are especially important in extremely elderly patients. Preoperative assessment of extremely elderly patients and formulation of an effective anesthetic plan according to the individual's profile can decrease the risks of anesthesia (21). The surgeon's skill was enhanced due to specialization and made the liver resection become safe. A special team including surgeons, physicians, anesthetists and nurses for unstable elderly patients can decrease morbidity and mortality (22). The environment of the operation room has improved (4), and the operative instruments have been updated, which could attenuate the stress of an operation. Positive and effective treatment in surgical intensive care unit (SICU) helps extremely elderly patients through the crisis after operation. Therefore, hepatic resection for extremely elderly patients with hepatobiliary malignancies should be performed at high-volume centers (20).

\section{Conclusion}

Hepatic resection for HCC and CRLM in patients aged 80 years or older who are in good general condition may be safe and acceptable under appropriate assessments of patients' physical condition, concomitant diseases and nutritional status as well as optimal perioperative management. For HCC, hepatic resection may be effective for patients whose hepatic resection can be performed with a negative surgical margin.

\section{Conflicts of Interest}

The Authors report no proprietary or commercial interest in any product mentioned or concept discussed in this article.

\section{Authors' Contributions}

Critical revision of the article for important intellectual content: T. Horiuchi; Conception and design of the study: K. Haruki, H. Shiba, T. Sakamoto; Collection and assembly of data: N. Saito, Y. Shirai, R. Iwase, Y. Fujiwara; Final approval of the article: K. Yanaga.

\section{References}

1 Anaya DA, Becker NS and Abraham NS: Global graying, colorectal cancer and liver metastasis: new implications for surgical management. Crit Rev Oncol Hematol 77(2): 100-108, 2011. PMID: 20206548. DOI: 10.1016/j.critrevonc.2010.02.003

2 Petrowsky $\mathrm{H}$ and Clavien PA: Should we deny surgery for malignant hepato-pancreatico-biliary tumors to elderly patients? World J Surg 29(9): 1093-1100, 2005. PMID: 16086216. DOI: 10.1007/s00268-005-1130-6

3 Huang J, Li BK, Chen GH, Li JQ, Zhang YQ, Li GH and Yuan YF: Long-term outcomes and prognostic factors of elderly patients with hepatocellular carcinoma undergoing hepatectomy. J Gastrointest Surg 13(9): 1627-1635, 2009. PMID: 19506976. DOI: $10.1007 / \mathrm{s} 11605-009-0933-4$

4 Jin $\mathrm{F}$ and Chung F: Minimizing perioperative adverse events in the elderly. $\mathrm{Br} \mathrm{J}$ Anaesth 87(4): 608-624, 2001. PMID: 11878732. DOI: $10.1093 / \mathrm{bja} / 87.4 .608$

5 Miyagawa S, Makuuchi M, Kawasaki S and Kakazu T: Criteria for safe hepatic resection. Am J Surg 169(6): 589-594, 1995. PMID: 7771622. DOI: 10.1016/s0002-9610(99)80227-x

6 Rahbari NN, Garden OJ, Padbury R, Brooke-Smith M, Crawford M, Adam R, Koch M, Makuuchi M, Dematteo RP, Christophi C, Banting S, Usatoff V, Nagino M, Maddern G, Hugh TJ, Vauthey JN, Greig P, Rees M, Yokoyama Y, Fan ST, Nimura Y, Figueras J, Capussotti L, Büchler MW and Weitz $\mathrm{J}$ : Posthepatectomy liver failure: a definition and grading by the International Study Group of Liver Surgery (ISGLS). Surgery 149(5): 713-724, 2011. PMID: 21236455. DOI: 10.1016/j.surg.2010.10.001

7 Koch M, Garden OJ, Padbury R, Rahbari NN, Adam R, Capussotti L, Fan ST, Yokoyama Y, Crawford M, Makuuchi M, Christophi C, Banting S, Brooke-Smith M, Usatoff V, Nagino M, Maddern G, Hugh TJ, Vauthey JN, Greig P, Rees M, Nimura Y, Figueras J, DeMatteo RP, Büchler MW and Weitz J: Bile leakage after hepatobiliary and pancreatic surgery: a definition and grading of severity by the International Study Group of Liver Surgery. Surgery 149(5): 680-688, 2011. PMID: 21316725. DOI: $10.1016 /$ j.surg .2010.12.002

8 Ferrero A, Viganò L, Polastri R, Ribero D, Lo Tesoriere R, Muratore A and Capussotti L: Hepatectomy as treatment of choice for hepatocellular carcinoma in elderly cirrhotic patients. World J Surg 29(9): 1101-1105, 2005. PMID: 16088422. DOI: $10.1007 / \mathrm{s} 00268-005-7768-2$

9 American Geriatrics Society Expert Panel on Postoperative Delirium in Older Adults: Postoperative delirium in older adults: best practice statement from the American Geriatrics Society. J Am Coll Surg 220(2): 136-148, 2015. PMID: 25535170. DOI: 10.1016/j.jamcollsurg.2014.10.019

10 Cescon M, Grazi GL, Del Gaudio M, Ercolani G, Ravaioli M, Nardo B and Cavallari A: Outcome of right hepatectomies in patients older than 70 years. Arch Surg 138(5): 547-552, 2003. PMID: 12742961. DOI: 10.1001/archsurg.138.5.547 
11 European Commission, Eurostat. Available at: http:// epp.eurostat.ec.europa.eu/portal/page/portal/eurostat/home/

12 Shirabe K, Kajiyama K, Harimoto N, Gion T, Tsujita E, Abe T, Wakiyama S, Nagaie T and Maehara Y: Early outcome following hepatic resection in patients older than 80 years of age. World $\mathbf{J}$ Surg 33(9): 1927-1932, 2009. PMID: 19603226. DOI: 10.1007/ s00268-009-0122-3

13 Melendez J, Ferri E, Zwillman M, Fischer M, Dematteo R, Leung D, Jarnagin W, Fong Y and Blumgart LH: Extended hepatic resection: a 6-year retrospective study of risk factors for perioperative mortality. J Am Coll Surg 192(1): 47-53, 2001. PMID: 11192922.

14 Kaibori M, Yoshii K, Hasegawa K, Ogawa A, Kubo S, Tateishi R, Izumi N, Kadoya M, Kudo M, Kumada T, Sakamoto M, Nakashima $\mathrm{O}$, Matsuyama $\mathrm{Y}$, Takayama $\mathrm{T}$ and Kokudo $\mathrm{N}$ : Treatment optimization for hepatocellular carcinoma in elderly patients in a Japanese nationwide cohort. Ann Surg 270(1): 121-130, 2018. PMID: 29608544. DOI: 10.1097/SLA.000000000 0002751

15 Kehlet H, and Wilmore DW: Multimodal strategies to improve surgical outcome. Am J Surg 183(6): 630-641, 2002. PMID: 12095591. DOI: $10.1016 / \mathrm{s} 0002-9610(02) 00866-8$

16 Wong-Lun-Hing EM, van Dam RM, Heijnen LA, Busch OR, Terkivatan T, van Hillegersberg R, Slooter GD, Klaase J, de Wilt JH, Bosscha K, Neumann UP, Topal B, Aldrighetti LA and Dejong $\mathrm{CH}$ : Is current perioperative practice in hepatic surgery based on enhanced recovery after surgery (ERAS) principles? World J Surg 38(5): 1127-1140, 2014. PMID: 24322177. DOI: 10.1007/s00268-013-2398-6

17 Coolsen MM, Wong-Lun-Hing EM, van Dam RM, van der Wilt AA, Slim K, Lassen K and Dejong CH: A systematic review of outcomes in patients undergoing liver surgery in an enhanced recovery after surgery pathways. HPB (Oxford) 15(4): 245-251, 2013. PMID: 23458424. DOI: 10.1111/j.1477-2574.2012. 00572.X
18 Bagnall NM, Malietzis G, Kennedy RH, Athanasiou T, Faiz O and Darzi A: A systematic review of enhanced recovery care after colorectal surgery in elderly patients. Colorectal Dis 16(12): 947956, 2014. PMID: 25039965. DOI: 10.1111/codi. 12718

19 Pawa N, Cathcart PL, Arulampalam TH, Tutton MG and Motson RW: Enhanced recovery program following colorectal resection in the elderly patient. World J Surg 36(2): 415-423, 2012. PMID: 22146943. DOI: $10.1007 / \mathrm{s} 00268-011-1328-8$

20 Caratozzolo E, Massani M, Recordare A, Bonariol L, Baldessin $\mathrm{M}$ and Bassi N: Liver resection in elderly: comparative study between younger and older than 70 years patients: outcomes and implications for therapy. G Chir 28(11-12): 419-424, 2007. PMID: 18035008 .

21 Muravchick S: Preoperative assessment of the elderly patient. Anesthesiol Clin North America 18(1): 71-89, 2000. PMID: 10935001.

22 Demetriades D, Sava J, Alo K, Newton E, Velmahos GC, Murray JA, Belzberg H, Asensio JA and Berne TV: Old age as a criterion for trauma team activation. J Trauma 51(4): 754-756, 2001. PMID: 11586171. DOI: 10.1097/00005373-200110000-00022
Received July 3, 2019

Revised July 24, 2019

Accepted July 25, 2019 